NBER WORKING PAPER SERIES

TREASURY BILL FUTURES AS

HEDGES AGAINST INFLATION RISK

Jayendu Patel

Richard Zeckhauser

Working Paper No. 2322

NATIONAL BUREAU OF ECONOMIC RESEARCH

1050 Massachusetts Avenue

Cambridge, MA 02138

July 1987

The Japanese Corporate Associates Program of the John F. Kennedy School of Government provided research support. David Braunschvig provided valuable research assistance. We thank participants in seminars at Boston University, Harvard University, and Northwestern University. The research reported here is part of the NBER's research program in Financial Markets and Monetary Economics. Any opinions expressed are those of the authors and not those of the National Bureau of Economic Research. 
NBER Working Paper \#2322

July 1987

\section{Treasury Bill Futures as Hedges Against Inflation Risk}

\section{ABSTRACT}

An important risk facing agents in a monetary economy arises from inflation uncertainty: in the U.S. for the 1953-84 period, unexpected quarterly inflation had a standard deviation of 2.18 . The costs of such uncertainty are likely to be even higher for multi-year contracts, since we estimate that a 18 unexpected inflation this year implies an upward revision of 0.438 for expected inflation for the forthcoming year and $1 \%$ for the years beyond that. The prospect of hedging inflation risk exposure using conventional financial instruments is bleak, as has been widely documented.

We develop a theoretical case for Treasury bill futures as a inflation risk hedge by jointly assuming that (1) the Fisher Hypothesis applies to Treasury bill yields, (2) the Unbiased Expectations Hypothesis (UEH) applies to futures prices, and (3) inflation is an autoregressive process. Our empirical analysis shows that Treasury bill futures can reduce single-period inflation risk by about 30-408. The expected cost of using such futures is close to zero, since we find that the Unbiased Expectations Hypothesis for Treasury bill futures cannot be rejected. Our results provide new indirect support for the Fisher Hypothesis.

Jayendu Patel

John F. Kennedy School of Government Harvard University

79 JKF Street

Cambridge, MA 02138
Richard Zeckhauser John F. Kennedy School of Government Harvard University 79 JFK Street

Cambridge, MA 02138 


\title{
TREASURY BILL FUTURES AS HEDGES AGAINST INFLATION RISK
}

Jayendu Patel and Richard Zeckhauser

\begin{abstract}
We have seen the great harm of unstable money. But can anything be done about it? Must we accept the evils as dispensations of Providence or Fate, as we accept earthquakes and tornadoes?

--Irving Fisher (1928: p. 107)
\end{abstract}

\section{INTRODUCTION}

An important risk facing all agents in a monetary economy arises from fluctuations in the purchasing power of the unit of account: in the U.S. economy, the dollar. If this risk prevails in the aggregate--that is, cannot be diversified--it becomes a significant consideration for the conduct of monetary and fiscal policy. But regardless of the macroeconomic policies chosen, individuals may attempt to respond to this risk. Irving Fisher (1928: p. 124) recommended that individuals do their best to reduce the costs of inflation risk, "making in the aggregate many millions of instances of adjustments to counteract the effects of unstable money."

Fisher's advice is hard to implement. Scientific empirical studies find that assets popularly believed to provide inflation hedges are ineffectual--see Bodie (1976), Fama and Schwert (1977), and Fama (1981). Fortunate1y, Fisher's (1930) own hypothesis that variations in nominal yields are driven by inflationary expectations provides the basis for constructing an inflation hedge. We show that a conjunction of:

(1) the Fisher Hypothesis, 
(2) the Unbiased Expectations Hypothesis applied to futures, and

(3) an autoregressive inflationary process,

implies that Treasury bill futures will provide a hedge against unexpected inflation. 1

Our empirical analysis verifies the potential for successful inflation hedging. We examine the period since 1976, when Treasury bill futures have been trading on the International Monetary Market in Chicago. Participation in Treasury bill futures is easy: the market is active ( $\$ 5-10$ billion daily trading volume) with low transactions costs ( $\$ 80$ for a round trip on a futures contract with face value of $\$ 1$ million). We find that a short position in Treasury bill futures generates cash flows that are positively correlated with unexpected inflation. We also discuss issues related to extending our inflation hedging results to a multiperiod setting.

Besides demonstrating a means of hedging against inflation, our work provides new support for the two important but contested conjectures that we invoke, i.e., the Fisher Hypothesis and the Unbiased Expectations Hypothesis. ${ }^{2}$

\section{TREASURY BILL FUTURES AS AN INFLATION RISK HEDGE: THEORY}

We consider two empirical economic conjectures: the Fisher Hypothesis (FH) applied to Treasury bill yields (subsection 2.1) and the Unbiased Expectations Hypothesis (UEH) applied to prices of Treasury bill futures (subsec-

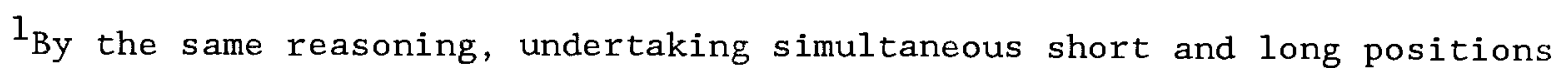
in the spot market for Treasury bills with different maturities is likely to provide an effective hedge against inflation. Of course, such a synthetic forward position would incur higher transactions costs than a position using futures contracts.

${ }^{2}$ Our support for the Fisher Hypothesis is indirect since our analysis assesses an implication and since we invoke a chain of derivations and auxiliary assumptions. 
tion 2.2). While there is an extensive sophisticated literature evaluating the FH, previous tests of the UEH may have been flawed. We provide correct tests and find that the UEH is sustained for Treasury bill futures. This result contrasts with the negative result for $\mathrm{UEH}$ applied to the forward rates implicit in the term structure. We examine the historical inflation process for the United States and confirm the autoregressivity of inflation (subsection 2.3). Joint consideration of the two conjectures and the empirical properties of inflation leads to our inflation hedging proposition (subsection 2.4).

\subsection{The Fisher Hypothesis}

Consider the decomposition of a single-period Treasury bill nominal yield, ${ }^{3} b_{t}$, into expected inflation, $E_{t-1} \pi_{t}$, and an ex ante real interest rate, $r_{t}$ :

(1) $\mathrm{b}_{t}=\mathrm{r}_{\mathrm{t}}+E_{\mathrm{t}-1} \pi_{\mathrm{t}}$.

Our maintained hypothesis throughout this paper is that expectations embedded in asset prices are best linear unbiased. In equation (1), the interest rates and the inflation rate are expressed as continuously compounded rates to deliver the convenient additive expression; the one-unit holding period for the Treasury bill to maturity from instant $t-1$ to $t$ is labeled by the closing instant (i.e., t); $r_{t}$ denotes the expected real return to be realized by holding the Treasury bill over period $t ; \pi_{t}$ is the inflation over the holding period $t ; E_{t-1} \pi_{t}$ is the one-step-ahead expectation of inflation over the holding period, conditional on all information available at the instant $t-1$ (when

\footnotetext{
${ }^{3}$ The distinction between ex ante and ex post nominal yields is irrelevant
} for single-period nominal Treasury bills. 
the yield on the Treasury bill is observed). More generally, $E_{\mathrm{t}-\mathrm{k}} \pi_{\mathrm{t}}$ denotes a $k$-period-ahead forecast of inflation.

We identify two versions of the FH expressed in equation (1): the Weak and the Strong. The Weak FH asserts that the ex ante real return on a nominal asset is statistically independent of expected inflation. ${ }^{4}$ The Strong $\mathrm{FH}$ asserts in addition that a substantial portion of variations in ex ante nominal yields is explained by variations in expected inflation. 5 Formally the additional restriction of the strong version is:

(2) variance $\left[E_{\mathrm{t}-\mathrm{k}^{\mathrm{r}}} \mathrm{r}_{\mathrm{t}-\mathrm{j}} \mathrm{r}_{\mathrm{t}}\right] \ll \operatorname{variance}\left[E_{\mathrm{t}-\mathrm{k}} \pi_{\mathrm{t}}-E_{\mathrm{t}-\mathrm{j}} \pi_{\mathrm{t}}\right], \mathrm{j}>\mathrm{k}>0$.

Fama (1975) provides the classic study of the Strong FH for Treasury bill yields; he concludes that the evidence does not reject the Strong FH. More recently, Fama and Gibbons (1982) find that the variance of the innovations in real returns is substantially smaller than that for the innovations in inflation for the United States (a ratio less than 0.01). But the debate over the validity of the $\mathrm{FH}$ is hardly settled. Summers (1983, 1984) interprets his evidence to reject the FH. Patel (1986), who corrects earlier inconsistent tests of the $\mathrm{FH}$ and updates the findings, discovers evidence from the Treasury bills of the United States, United Kingdom, and Canada that is consistent with the Strong $\mathrm{FH}$.

But Patel's evidence, for the period since World War II, indicates that real returns are negatively related to inflation regimes (for example, the high inflation regime of the 1970s was accompanied by negative real rates,

${ }^{4}$ Fisher would probably have qualified this statement by saying that it holds only in the long run.

${ }^{5}$ A third version, articulated in Miller and Upton (1974), is that the nominal return on nominal bonds is equal to the sum of the (real) return on an otherwise identical purchasing-power-indexed bond and expected inflation. 
while the low inflation era in the Reagan years has been accompanied by positive real rates). If the strong FH fails in this fashion, the investor at risk for unexpected inflation faces an additional class of risks, those associated with unexpected regime shifts in ex ante real rates of return. Recontracting period by period would not mitigate this risk.

In contrast to the above-cited papers that directly test the $\mathrm{FH}$, this paper develop and tests an indirect implication of the FH: the evidence is not from spot yields but from cash flows associated with futures positions.

\subsection{Futures as Predictors of Future Spot Rates}

A popular model for futures pricing is the Unbiased Expectations Hypothesis. When applied to Treasury bill futures, the UEH becomes: 6

(3) $\quad \mathrm{F}_{\mathrm{t}}^{\mathrm{k}}=E_{\mathrm{t}} \mathrm{B}_{\mathrm{t}+\mathrm{k}}+\delta, \delta=0$.

Here $F_{t}^{k}$ is the futures price prevailing at time $t$ for a contract with maturity date $k$ periods hence (i.e., maturity date $t+k$ ); $B_{t+k}$ is the spot Treasury bill price prevailing at time $t+k$; and $E_{t} B_{t+k}$ is the expectation of $B_{t+k}$ conditional on information available at time $t$.

Direct tests of (3) need care since $F_{t}^{k}$ and $B_{t+k}$ are nonstationary--see the autocorrelations reported below in table 3. Earlier empirical studies of the UEH overlooked estimation and testing problems that arise with nonstationary price series, rendering their conclusions suspect. (See Granger and New-

${ }^{6}$ Under mildly restrictive conditions, Jarrow and Oldfield (1981) show that the pricing of futures contracts is identical to that of forward contracts. In such circumstances, the price of a Treasury bill futures contract will reflect the forward yield implicit in spot Treasury bills. Combining this result with the pure expectations theory of the term structure of interest rates (assumed to hold for relevant maturities) and rational expectations, the Treasury bill futures price becomes an unbiased forecast of the future spot Treasury bill price (approximately). Of course, this is not the only setting in which the UEH holds for Treasury bill futures. 
bold (1986) on spurious regressions in such contexts.) We provide fresh empirical evidence in support of the UEH, taking proper account of the (near) unit autoregressive root in the price series that is associated with unconditional mean nonstationary behavior. Our testing of the UEH (which indirectly assesses the ex ante cost of adding Treasury bill futures to a portfolio) also highlights some pitfalls of using Ordinary Least Squares (OLS) estimation in such circumstances.

Consider the following regression:

(4) $B_{t+k}=\alpha+\beta F_{t}^{k}+u_{t+k}$.

Under the hypothesis of equation (3), the restrictions on regression (4) are that $\alpha=0, \beta=1.0$, and $u_{t+k}$ is stationary with mean zero. Market efficiency implies that $u_{t+k}$ is unpredictable given the information set available at time t. In the case of nonoverlapping data (i.e., where the data sampling interval is not less than the length of the holding period [k]), $u_{t+k}$ should be white noise. In the case of overlapping data, $u_{t+k}$ will be a moving average of the order of the overlap.

For our purposes, we invoke the innocuous assumption that spot and futures prices converge at maturity:

(5) $\mathrm{F}_{\mathrm{t}+\mathrm{k}}^{0}=\mathrm{B}_{\mathrm{t}+\mathrm{k}}$,

where $\mathrm{F}_{\mathrm{t}+\mathrm{k}}^{0}$ is the futures price with zero time left to maturity. The data on Treasury bill futures were drawn from various issues of the International Monetary Market yearbooks. The OLS estimates for the regression (4) for values of $t$ from one to six months, using (5) to substitute the maturity month futures price for the maturity month spot price, are presented in table 1.7

${ }^{7}$ Stock (1985) shows that OLS provides consistent estimates of regressions like equation (4) even when the variables are nonstationary as long as the errors are stationary. 
TABLE 1

FUTURES CONTRACT PRICES AS UNBIASED

PREDICTORS OF FUTURE SPOT PRICES

Sample Period: 76Q3-83Q1

\begin{tabular}{|c|c|c|c|c|}
\hline \multicolumn{5}{|c|}{$\mathrm{F}_{\mathrm{t}+\mathrm{k}}^{0}=\alpha+\beta \mathrm{F}_{\mathrm{t}}^{\mathrm{k}}+\mathrm{u}_{\mathrm{t}+\mathrm{k}}$} \\
\hline \multirow[t]{2}{*}{$\begin{array}{c}k \\
\text { (months) }\end{array}$} & $\alpha$ & $\beta$ & $\begin{array}{l}\text { Durbin- } \\
\text { Watson }\end{array}$ & $\sigma_{\mathrm{u}}$ \\
\hline & \multicolumn{4}{|c|}{ Nonoverlapping Data, Quarterly Observations ${ }^{a}$} \\
\hline 1 & 1.53 & 0.98 & 2.05 & 0.34 \\
\hline 2 & 3.60 & 0.96 & 2.30 & 0.53 \\
\hline \multirow[t]{2}{*}{3} & 23.38 & 0.76 & 2.01 & 0.66 \\
\hline & \multicolumn{4}{|c|}{ Overlapping Data, Quarterly Observations ${ }^{b}$} \\
\hline 4 & 15.03 & 0.84 & 1.67 & 0.64 \\
\hline 5 & 15.22 & 0.84 & 1.30 & 0.67 \\
\hline 6 & 34.65 & 0.65 & 1.29 & 0.76 \\
\hline \multicolumn{5}{|c|}{$\begin{array}{l}{ }^{a} \text { None of the residual autocorrelations was significantly different from } \\
\text { zero. }\end{array}$} \\
\hline $\begin{array}{l}\mathrm{b}_{\text {The }} \\
\text { every qua } \\
\text { overlappi } \\
\text { by the nu } \\
\text { autocorre }\end{array}$ & $\begin{array}{l}\text { Eor the } \\
\text { ille th } \\
\text { regre } \\
\text { thesis } \\
\text { was s }\end{array}$ & $\begin{array}{l}\text { wher } \\
\text { iods } \\
\text { nsis }\end{array}$ & $\begin{array}{l}\text { rlap b } \\
\text { quart } \\
\text { an MA }\end{array}$ & $\begin{array}{l}\text { sample once } \\
\text { residuals with } \\
\text { ress as predicted } \\
\text { residual }\end{array}$ \\
\hline
\end{tabular}

The residuals appear to be stationary, as indicated by the Durbin-Watson statistic (and by the residual autocorrelations [not reported]); they appear to be white noise with nonoverlapping data and moving-average of the first order, MA(1), with the overlap of one period. This finding is consistent with the null hypothesis. 8

${ }^{8}$ Further, in tests not reported, we found that the table 1 residuals are uncorrelated with past money growth, past changes in Treasury bill yields, and past changes in inflation (also see related results in table 2). 
A superficial examination of the coefficient estimates suggests that $\alpha$ is greater than zero and that $\beta$ is less than 1.0. (Tests based on conventional OLS standard errors indicate rejections of $\alpha=0$ and $\beta=1.0$.) However, since the variables in the OLS-estimated regression are (near) nonstationary, the OLS estimation is likely to be biased, possibly by a substantial amount for the small sample size of 31 observations. ${ }^{9}$

We use Monte Carlo simulations to assess whether the table 1 estimates are likely to have arisen under the null hypothesis of $\alpha=0$ and $\beta=1.0$. Details of the simulation method appear in the appendix. Briefly, we simulate the Treasury bill prices using a univariate model consistent with the sample period properties. We then compute simulated futures prices such that they correspond to efficient forecasts of the future Treasury bill prices. In our simulations, the UEH is true by construction.

We regress the simulated Treasury bill prices on the simulated futures prices, obtaining estimates of $\alpha$ and $\beta$ based on 31 observations for Treasury bill futures from maturities of one to six months. We repeat this 1,000 times. The histograms in figure 1 summarize the simulation results.

The actual estimates from table 1 , shown as asterisks in these histograms, are seen to be quite typical of the estimates from the simulation. 10 A sense of the power of tests is obtained by examining simulation results from setting $\beta=0.1$, which are shown in figure 2 . There we observe

${ }^{9}$ Stock (1985) shows that (1) the OLS estimates of a regression like equation (4) will have a bias that is a function of sample size (decreasing as sample size increases) and (2) the standard errors of the estimates are not as computed by conventional oLS routines.

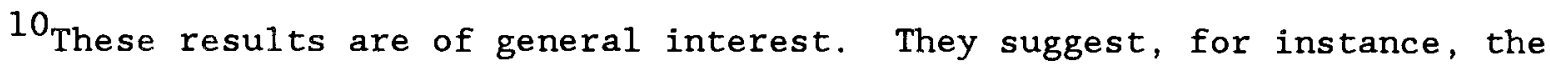
nature of the corrections needed in tests of forward exchange rates as predictors of future spot rates. 


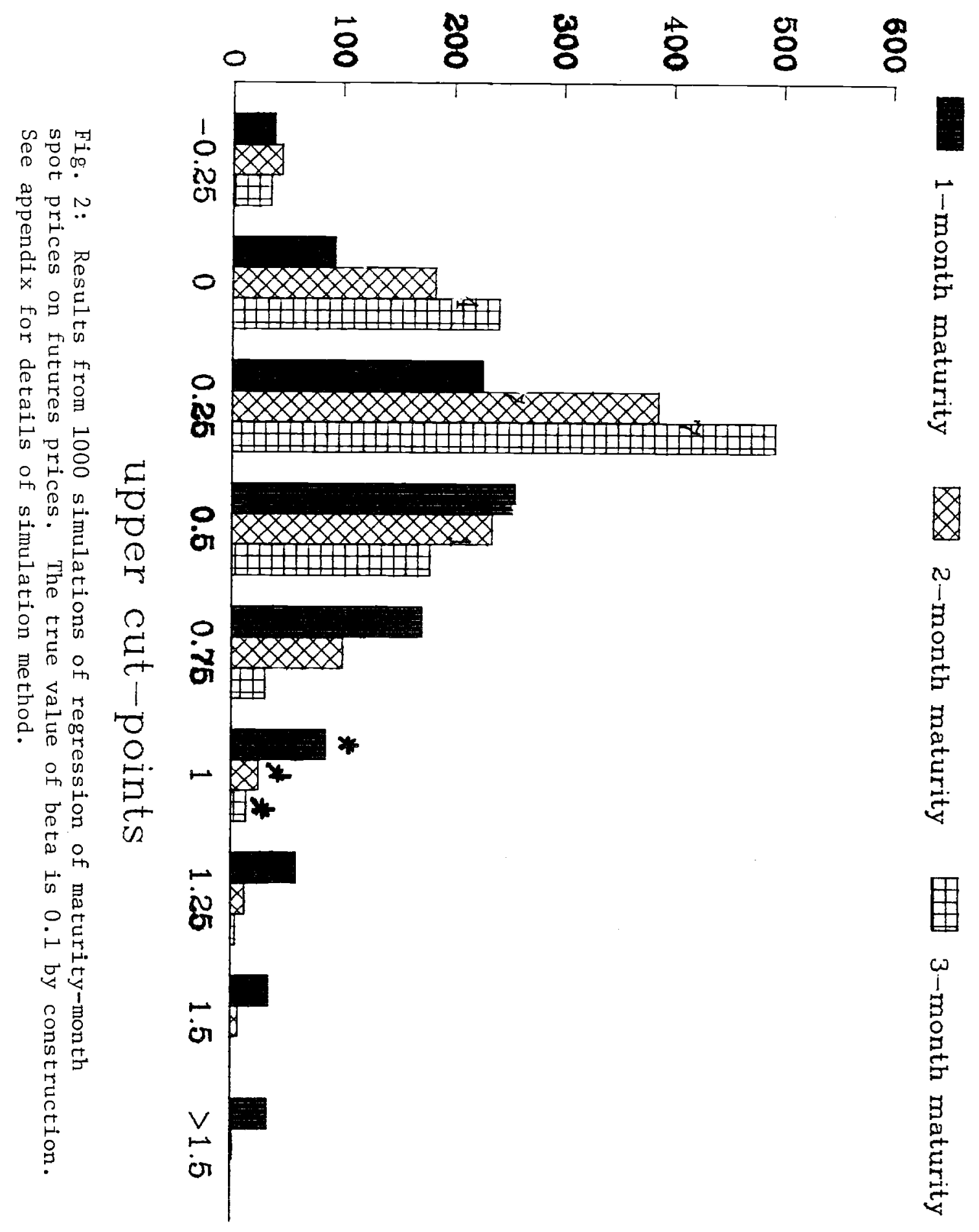




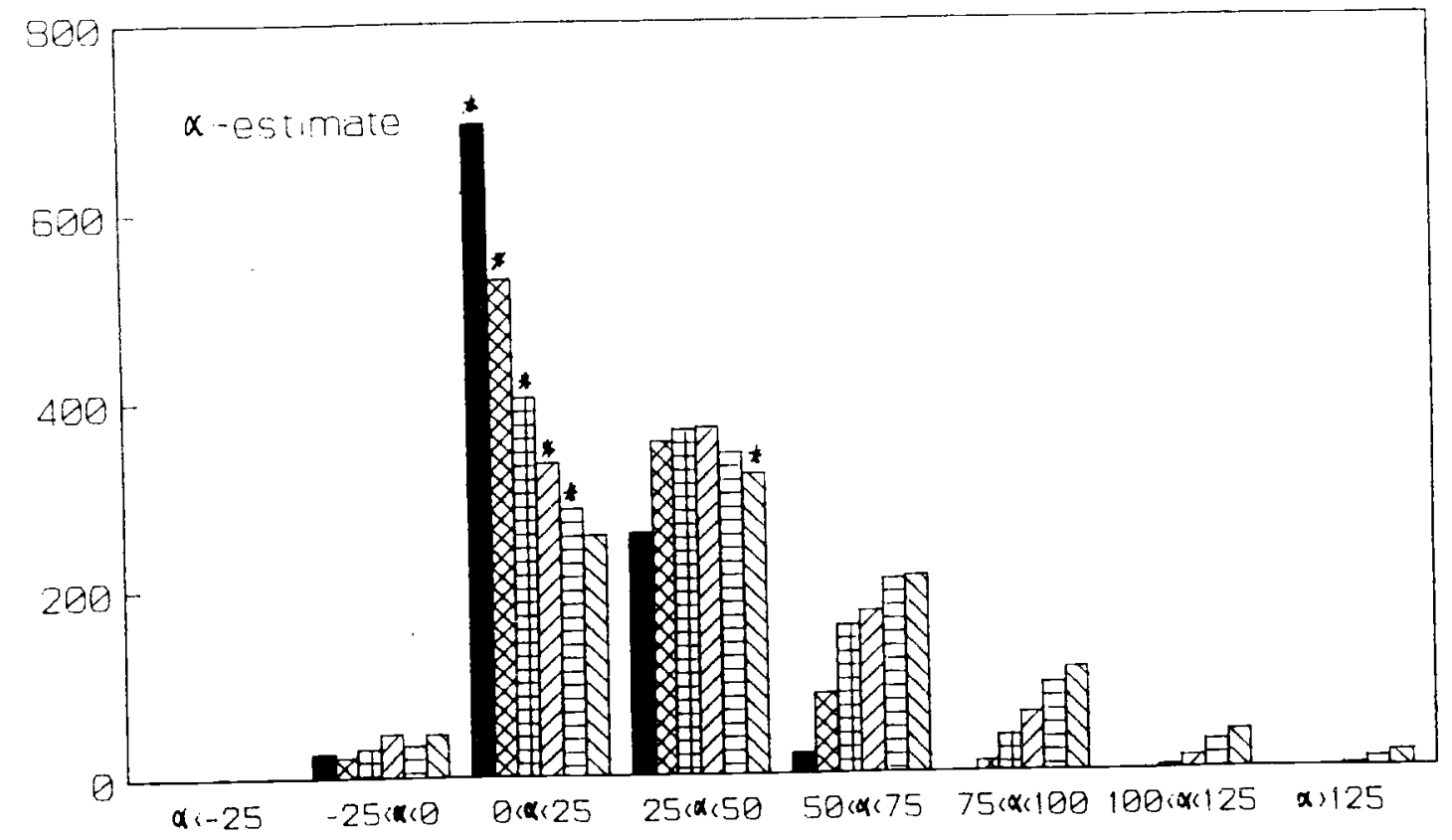

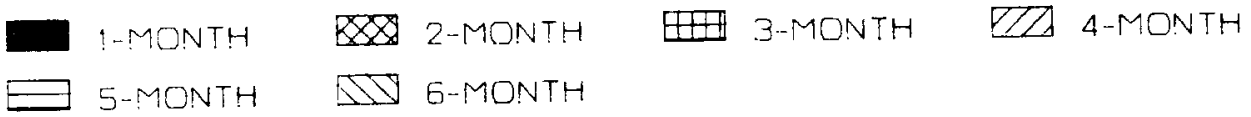

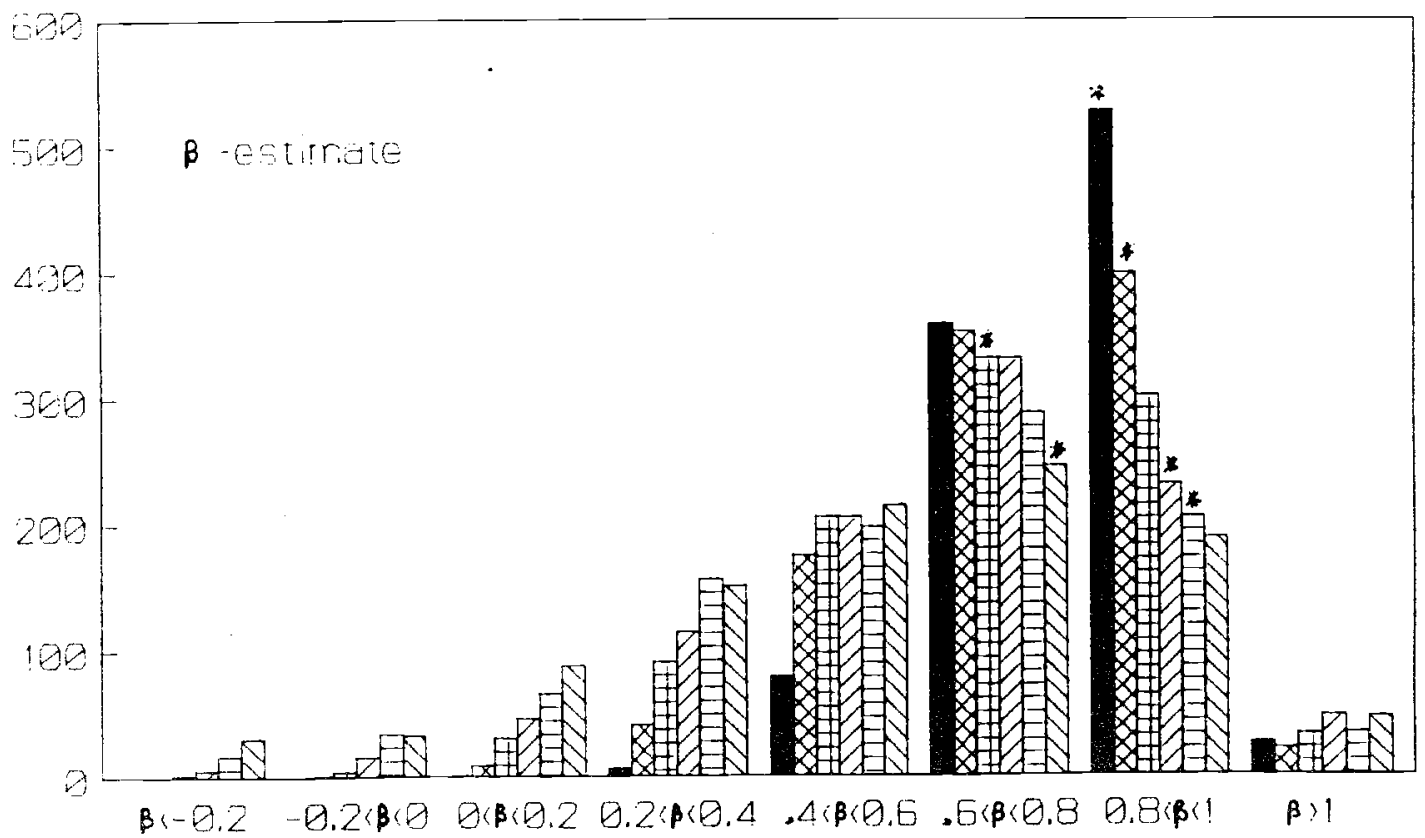

[1. 1: Results from 1000 simulations of regression of maturity-month spot prices on futures prices (with maturities from 1 month to 6 months). The Unbiased Expectations Xypothesis is true by construction. The upper panel shows the distribution of the constant $(\alpha)$ estimate, in the UEH regression (see equation [12]); the lower panel shows the distribution of the rrojection-coefficient $(\beta)$ estimate. The true value of $\alpha$ is zero as is niter. 
that the table 1 estimates (again shown as asterisks) are quite atypical of a situation where the true $\beta$ is 0.1 . We conclude that the table 1 results are consistent with the UEH.

Simpler tests for the UEH, based on examining the change in the futures price from to $t+k$, can also be constructed. It follows from equation (5) that $E_{t} B_{t+k}=E_{t} F_{t+k}^{k}$. Combine this result with the UEH in equation (3) to obtain the hypothesis that the net cash flow from holding the futures contract, $C_{t+k}^{k} \equiv F_{t+k}^{0}-F_{t}^{k}$, has mean zero and is statistically independent of the information available when the position is initiated (i.e., time $t$ when $\mathrm{F}_{\mathrm{t}}^{\mathrm{k}}$ is set). Tests reported in table 2 fail to reject this hypothesis of zero mean as well as the hypothesis of independence (specialized to absence of correlation) of $c_{t+k}^{k}$ with variables that are a subset of available information at $t$ such as (a) past $C^{k}$, (b) past growth in Ml (currency + demand deposits), and (c) past inflation.11

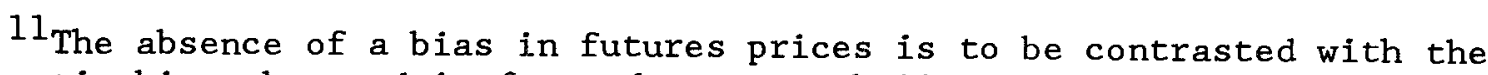
systematic bias observed in forward Treasury bill contracts (constructed synthetically using spot Treasury bills). Using 3 -month and 6 -month bills in the 1960-85 period, we confirmed the results of Branch (1978), Lang and Raasche (1978), and others, that the implicit forward price was a systematically downward biased forecast of the future spot price. The source of the divergence between futures and forward prices remains to be satisfactorily answered: contending explanations include differential tax treatments, market segmentation due to relatively high transactions costs precluding exact arbitrage, and interest rate risk for futures due to marking-to-the-market. We did examine synthetic forward positions as hedges against inflation risk for 1960-75 when Treasury bill futures did not trade (but 3-month and 6month Treasury bills were available). While results similar to those presented in section 3 were obtained, we deemphasize them because of the systematic divergence between forward prices and expectations of future spot prices which also imply an expected cost for hedging inflation risk. 
TABLE 2

UNPREDICTABILITY OF CASH FLOWS FROM FUTURES POSITIONS

Sample Period: 76Q3-83Q2

\begin{tabular}{l|c|c}
\hline \multicolumn{2}{|c|}{$C_{\mathrm{t}+3}^{3}=\alpha+\beta_{1} \mathrm{x}_{\mathrm{t}}+\beta_{2} \mathrm{x}_{\mathrm{t}-3}+\beta_{3} \mathrm{x}_{\mathrm{t}-6}+\mathrm{u}_{\mathrm{t}}$} \\
\hline \multicolumn{1}{c|}{$\mathrm{x}_{\mathrm{t}}$} & F-test: $\alpha=\beta(\mathrm{L})=0$ & $\begin{array}{c}\text { Significance Leve1 } \\
\text { p-value (8) }\end{array}$ \\
\hline $\begin{array}{l}\text { Inflation } \\
\text { Money Growth } \\
\text { Industrial Produc- } \\
\text { tion Growth } \\
\text { Past Cash Flows }\end{array}$ & 0.86 & 50 \\
& 0.22 & 92 \\
& $4.74^{\mathrm{a}}$ & $31^{\mathrm{a}}$ \\
\hline
\end{tabular}

a The test for past cash flows is simply for absence of serial correlation. This test is a modified Box-Pierce statistic, which is distributed chisquare with three degrees of freedom under the null hypothesis.

None of the tests in table 2 rejects the null hypothesis. In sum, the evidence suggests that Treasury bill futures contracts are efficient, unbiased predictors of future spot Treasury bill prices. ${ }^{12}$ This implies that there is no ex ante premium when they are used. We now examine the inflation process.

\subsection{Univariate Model for Inflation}

After we observe the inflation in period $t-1$ (from instant $t-2$ to instant $t-1$ ), how should we revise our forecast for $\pi_{t}$ ? In other words, how should our forecast $E_{\mathrm{t}-1} \pi_{\mathrm{t}}$ differ from the one formed earlier, $E_{\mathrm{t}-2} \pi_{\mathrm{t}}$ ? The appropriate revision depends on the process governing inflation. Fama and Gib-

12 Our examination of efficiency is restricted to predictions of quarterly revisions of prices. Thus, for example, we have little to say about intraday trading efficiency of the futures market discussed in Elton et al. (1984). 
bons (1984) show that the inflation forecast conditional solely on past inflation provides a good approximation to the implicit inflation forecast of the Treasury bill market (which presumably uses all information efficiently). If valid, the result of Fama and Gibbons suggests a simple urivariate model of inflation forecast revision.

The autocorrelations of the inflation process are large and persistent. The autocorrelogram suggests a unit root in an autoregressive representation: inflation appears to be a mean nonstationary process. (Formal tests, not reported, of a unit autoregressive root following Dickey and Fuller (1981) are not rejected.) A single differencing is needed to obtain mean stationarity.

Suppose, then, that $\Delta \pi_{t}$ is a linear, stationary, stochastic process where $\Delta$ is the backward differencing operator (i.e., $\Delta \pi_{t} \equiv \pi_{t}-\pi_{t-1}$ ). 13 In this case, we can use the Wold theorem to express $\Delta \pi_{t}$ in terms of independent and identically distributed innovations, $u_{t}$ :

(6) $\Delta \pi_{t}=\theta(\mathrm{L}) \mathrm{u}_{\mathrm{t}}$.

Here, $\theta(L) \equiv 1+\theta_{1} L+\theta_{2} L^{2}+\ldots$ is a lag polynomial that converges for $L$ inside or on the unit circle; ${ }^{14} \mathrm{~L}$ is the lag operator (i.e., $\mathrm{Lx}_{\mathrm{t}}=\mathrm{x}_{\mathrm{t}-1}$ ). The representation (6) for inflation is the familiar integrated moving average model, $\operatorname{IMA}(1, q)$, where we have $q$ terms in the lag polynomial, $\theta(\mathrm{L}) .15$ It now follows that

$13 \mathrm{~A}$ nonlinear model may be more appropriate to allow the conditional distribution of inflation to shift with the level. For instance, we may conjecture that inflation follows an elastic random walk.

14 We additionally assume invertibility for the differenced inflation process--this ensures identification of the moving average parameters.

15 We follow standard time-series notation. $\operatorname{IMA}(d, q)$ refers to a process that needs to be differenced d times to be rendered stationary; the stationarized process is a moving average of order $q$. 
(7) $E_{\mathrm{t}-1} \pi_{\mathrm{t}}-E_{\mathrm{t}-2} \pi_{\mathrm{t}}=\left(1+\theta_{1}\right) \mathrm{u}_{\mathrm{t}-1}$

where $\theta_{1}$ is the first parameter in the moving-average representation of equation (6).

Equation (7) states that the one-period revision in forecasts for a given future inflation is linearly related to the most recent innovation in inflation (assuming that $\theta_{1} \neq-1$ ). We estimated an $\operatorname{IMA}(1,1)$ model for U.S. quarterly inflation for the period of our study, $1976-86 ;{ }^{16}$ the results appear in table 3 .

TABLE 3

IMA $(1,1)$ MODEL FOR CPI INFLATION

$\Delta \pi_{t}=\mu+\theta u_{t-1}+u_{t} ; u_{t}$ is zero-mean white noise

\begin{tabular}{|c|c|c|c|c|c|c|c|}
\hline & & & & Residual & Autoco & elatic & at Lags \\
\hline Period & $\mu$ & $\theta$ & $\sigma_{\mathrm{u}}$ & 1 & 2 & 3 & 4 \\
\hline $76-86$ & $\begin{array}{l}-0.10 \\
(0.19)\end{array}$ & $\begin{array}{l}-0.52 \\
(0.13)\end{array}$ & 2.61 & 0.03 & -0.22 & 0.24 & 0.19 \\
\hline $76-82$ & $\begin{array}{l}-0.09 \\
(0.30)\end{array}$ & $\begin{array}{l}-0.46 \\
(0.19)\end{array}$ & 2.81 & 0.02 & -0.21 & 0.29 & 0.17 \\
\hline $83-86$ & $\begin{array}{c}0.01 \\
(0.21)\end{array}$ & $\begin{array}{l}-0.68 \\
(0.21)\end{array}$ & 2.30 & 0.02 & -0.23 & 0.23 & 0.15 \\
\hline
\end{tabular}

NOTE: The standard errors of the coefficient estimates are in parentheses.

Standard diagnostic tests (see Granger and Newbold (1986)) based on fitting higher-order models and examination of the residual autocorrelations indicate that the IMA $(1,1)$ model is adequate for this period. Examining two subperiods does not indicate any severe instability problems. In the IMA $(1,1)$ case where only $\theta_{1}$ is nonzero in equation (6), we can extend (7) to

${ }^{16}$ The inflationary processes observed for the United Kingdom and Canada also appear to be $\operatorname{IMA}(1,1)$. 
(8) $E_{\mathrm{t}-1} \pi_{\mathrm{t}}-E_{\mathrm{t}-\mathrm{k}} \pi_{\mathrm{t}}=\left(1+\theta_{1}\right)\left(\mathrm{u}_{\mathrm{t}-1}+\mathrm{u}_{\mathrm{t}-2}+\ldots+\mathrm{u}_{\mathrm{t}-\mathrm{k}}\right)$.

Thus, the revision between any two dates in an inflation forecast for a fixed future period is linearly related to the net surprise in inflation experienced between the two dates. 17

\subsection{Hedging Purchasing Power Risk}

The substantiated individual hypotheses of subsections $2.1,2.2$, and 2.3 jointly imply that Treasury bill futures will hedge purchasing power risk. The argument follows. Suppose we are to receive a nominal unit of currency $(\$ 1)$ in the future, say time $t$. Our expectation, as of time $t-1$, of the real value of the $\$ 1$ to be received is $E_{t-1}\left(1 / P_{t}\right)$, where $P_{t}$ is the level of the relevant price index that prevails at $t$. The risk is:

$$
\left(1 / P_{t}\right)-E_{t-1}\left(1 / P_{t}\right) \approx-u_{t-1}, \operatorname{smal1}\left|u_{t-1}\right|,
$$

where $u_{t-1}$ is the unexpected inflation experienced over the period.

Assumptions: The maintained assumptions are the FH for spot Treasury bill yields, the UEH for Treasury bill futures prices, an IMA(1,q) model for the inflation process, and small unexpected inflation.

Proposition: At $t-1$, sell short $1 /\left(1+\theta_{1}\right)$ units of Treasury bill futures contracts, where each unit calls for delivery at $t$ of Treasury bills with face value of $\$ 1$ million. (Here $\theta_{1}$ is the first moving-average coefficient in the IMA(1,q) inflationary process.) This will hedge against purchasing power risk over the same period (see equation (8)) such that a cash flow of approximately 17 While equaton ( 7 ) continues to apply for an $\operatorname{IMA}(1, q)$ process, $q \geq 1$,
equation ( 8 ) for two periods has to be modified to:

$$
E_{\mathrm{t}-1} \pi_{\mathrm{t}}-E_{\mathrm{t}-3} \pi_{\mathrm{t}}=\left(1+\theta_{1}\right) \mathrm{u}_{\mathrm{t}-1}+\left(1+\theta_{1}+\theta_{2}\right) \mathrm{u}_{\mathrm{t}-2} \text {. }
$$

The extension to a $k$-period revision is straightforward. 
$\$ 10,000$ will be generated per percentage point of unexpected inflation. There is no ex ante cost (except for small transactions costs) for undertaking the hedge. 18

Proof: Follows from equations (1), (2), (3), (7), and (9). ${ }^{19}$ Briefly, unexpected inflation is associated with a revision in expectations of future inflation rates because of the autoregressive nature of inflation. The FH implies that this revision in expected inflation rates is associated with a revision in Treasury bill prices. But futures prices are tied to spot prices through the assumed UEH. Thus we have a cash flow in the futures position associated with unexpected inflation. There is no ex ante cost of undertaking a hedge using Treasury bill futures since the UEH applies. (For inflation hedging with possibly nonzero ex ante costs, we need only a linear relation between the futures price and the expected future spot price rather than the stronger UEH relation.)

Hedging with Treasury bill futures can protect both against the risks of regime changes (discussed in subsection 2.1) and against unexpected inflation within regimes. ${ }^{20}$ We do not investigate the benefits of such joint hedging prospects. (Also, effective implementation of our inflation hedging strategy

${ }^{18}$ There are two types are transactions costs, both of which we ignore in our analysis. One involves direct brokerage costs associated with entering and exiting the futures position. The other is associated with ensuring a minimum maintenance margin in the face of possible adverse daily markings-tothe-market. (The opportunity cost of lost interest on the posted margin can be avoided by using interest-bearing assets as collateral.)

${ }^{19}$ The flow from the futures position is obtained in terms of percentage of original futures price rather than of dollar flows; the expression in terms of dollars is an approximation.

${ }^{20}$ Since we have one hedging instrument and two imperfectly correlated risks, the risk-minimizing strategy will be suboptimal for each risk individually. 
may require taking a fraction of the standard $\$ 1$ million Treasury bill futures contracts. Presumably, if inflation risk hedging were of significant importance, services would arise to break down such contracts.) ${ }^{21}$

As long as inflation is $\operatorname{IMA}(1,1)$, which is consistent with the U.S. experience, the above proposition applies to a k-interval hedging period without modification. A straightforward generalization when inflation is IMA(d, q), $d \geq 1$, can also be derived. Empirical evidence on our proposition is provided in the next section. The examination for hedging potential can be interpreted as an indirect joint test of the $\mathrm{FH}$ and UEH, which complements other direct tests. (The third condition of autoregressivity of inflation is noncontroversial.)

\section{INFLATION RISK HEDGING}

We assess the inflation risk hedging potential for the sample period of 1976-86, which covers 42 futures contracts. The strategies assessed involve holding the futures contract to maturity. Analyses of strategies that closed out a futures position before the maturity month did not lead to materially different results.

\section{I Measures of Hedge Effectiveness}

Bodie (1976), in evaluating common stocks as a hedge against inflation, measures hedge effectiveness in terms of the reduction in variance achieved

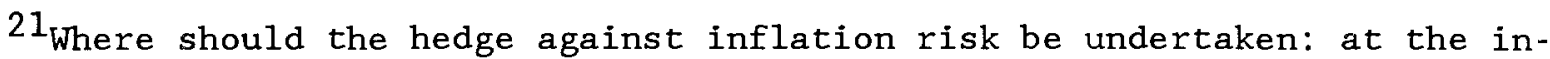
dividual or the corporate level? Individuals could tailor their holdings and degree of protection to their own portfolio and degree of risk aversion. But corporation-level provisions might benefit from economies of scale; protection might avoid agency problems with corporate executives. Moreover, given difficulties of contracting (e.g., problems associated with bankruptcy), it is perhaps desirable for firms with serious exposure to hedge themselves. 
for a portfolio of nominal bonds and stocks relative to that of an all-bond portfolio. Such a measure does not fit our purposes, because it does not separate the risk due to unexpected inflation from the risk due to changing real returns embedded in the pricing of bonds. Fama and MacBeth (1974) propose that a security represents an inflation hedge if its real return is independent of inflation. This definition is well suited to studying the Fisherian idea that for indiviudual assets there is a separation between innovations in the nominal sector (like unexpected inflation) and real rates. A comprehensive study of the capacity of assets to hedge against inflation in this sense is in Fama and Schwert (1977). However, an asset that is a perfect hedge according to the Fama and MacBeth definition cannot reduce the loss from inflation risk of other assets (though leveraged purchases of assets that are based on assuming nominal indebtedness clearly offer an inflation hedge).

Our measure of hedge effectiveness focuses on how well asset returns correlate with unexpected inflation. This specification of hedging effectiveness is consistent with most of the futures literature, such as Ederington (1979). In the context of our proposition, an asset (like Treasury bill futures) will be a desirable inflation hedge if its returns are correlated with unexpected inflation and its inclusion does not reduce the expected real return of the individual's portfolio.

\subsection{Inflation Proxies}

Since unexpected inflation is not directly measured, we consider a variety of proxies summarized in table 4. 
TABLE 4

PROXIES OF UNEXPECTED INFLATION

\footnotetext{
Based on Consumer Price Index:

$\mathrm{UD}_{\mathrm{t}} \equiv$ based on Data Resources Inc. (DRI) forecast of CPI inflation

$\mathrm{UFH}_{t} \equiv$ based on $\mathrm{FH}$, unbiased market expectations, and constant ex ante real returns but for regime shifts; see Patel (1986).

$\Delta \pi_{t} \equiv$ based on a random-walk model for inflation.

Based on GNP Deflator:

$\mathrm{UASA}_{t}=$ based on mean forecast reported in survey by American Statistical Association/National Bureau of Economic Research.

UDRI $_{t} \equiv$ based on DRI forecast of GNPD inflation
}

The unexpected inflation proxies should have zero mean and be serially uncorrelated. Table 5 reports univariate sample statistics for the variables of interest where ${ }^{0}{ }^{0}$ ' is the futures price at maturity and $C_{t}^{k}\left[=F_{t-k}^{k}-F_{t}^{0}\right]$ is the cash flow from holding a futures position from $k$ periods before maturity until maturity. 
TABLE 5

SUMMARY STATISTICS

Sample Period: 76Q3-86Q4

\begin{tabular}{|c|c|c|c|c|c|c|}
\hline Variable & Mean & Std. Dev. & \multicolumn{4}{|c|}{ Autocorrelations at Lags: ${ }^{a}$} \\
\hline $\mathrm{F}^{0}$ & $97.86^{*}$ & $0.81^{*}$ & .73 & .56 & .56 & .44 \\
\hline$c^{3}$ & -0.02 & 2.20 & -.15 & -.21 & .25 & -.04 \\
\hline$\pi_{t}(\mathrm{CPI})$ & $6.39^{*}$ & $3.99^{*}$ & .72 & .60 & .66 & .56 \\
\hline$\pi_{t}($ GNPD $)$ & $6.09^{*}$ & $2.28^{*}$ & .84 & .74 & .68 & .55 \\
\hline
\end{tabular}

Proxies for Unexpected Inflation Based on $\mathrm{CPI}^{\mathrm{b}}$

\begin{tabular}{|c|c|c|c|c|c|c|}
\hline $\mathrm{UFH}_{\mathrm{t}}$ & 0.08 & 1.81 & .02 & -.21 & .25 & -.05 \\
\hline $\mathrm{UD}_{\mathrm{t}}$ & 0.03 & 2.18 & .19 & .06 & .43 & \\
\hline$\Delta \pi_{t}$ & -0.09 & 2.89 & -.30 & -.32 & .22 & \\
\hline
\end{tabular}

Proxies for Unexpected Inflation Based on GNPD ${ }^{b}$

UASA $_{t}$

$-0.18$

1.26

$\begin{array}{llll}.31 & .03 & .42 & .33\end{array}$

$\mathrm{UDRI}_{\mathbf{t}}$

$-0.70$

1.16

$\begin{array}{llll}.05 & .26 & -.09 \quad .25\end{array}$

NOTES: (1) The asterisked estimates may not correspond to population values since the underlying series appear mean nonstationary.

(2) The sample period for $\pi$ (GNPD), UD, ASA/NBER, and DRI is 76Q3-85Q1.

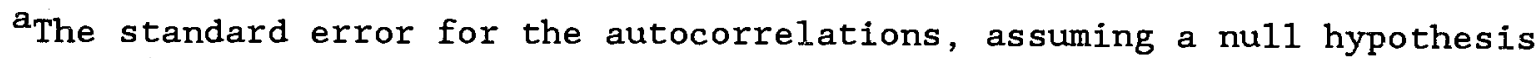
of white noise, is 0.18 .

${ }^{b}$ See table 4 for definition of unexpected inflation proxies.

None of the means for the unexpected-inflation proxies is statistically significantly different from zero. The proxies of unexpected inflation are consistent with ex ante unbiased forecasts--their overall autocorrelations are close to zero except for UASA and possibly $\Delta \pi$, both of which we find in later tests to provide anomalous results for our null hypothesis. The slow decay of 
autocorrelations in the inflation series (corresponding to unexpected inflation if the inflation forecast is simply the sample mean) is largely (and properly) eliminated in our proxies.

\subsection{Quality of Inflation Hedge}

How effective empirically is the quality of the inflation hedge provided by Treasury bill futures? Our hedging proposition (see section 2.4) predicts that the cash flow from a Treasury bill futures contract will be negatively correlated with the contemporaneous surprise in inflation. These crosscorrelations and covariances with alternative proxies of unexpected inflation are given in table 6.

TABLE 6

COVARIANCES/CORRELATIONS OF UNEXPECTED INFLATION PROXIES AND CASHFLOW FROM FUTURES POSITION

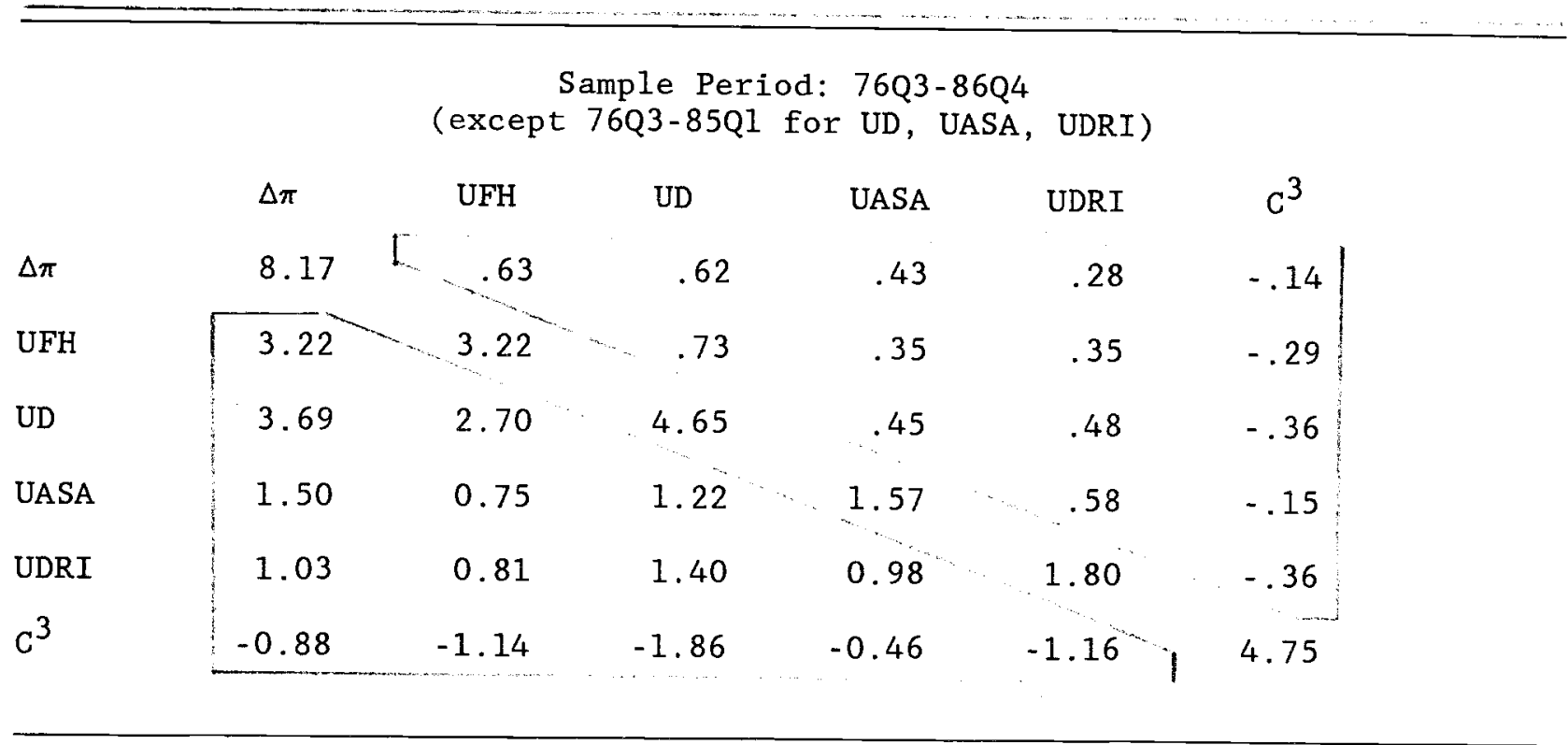

NOTE: The on-diagonal entries are variances. The super-diagonal entries (upper triangle) are correlations. The sub-diagonal entries (lower triangle) are covariances. $\Delta \pi$, UFH, and UD are for CPI inflation while UASA and UDRI are for GNPD inflation--see table 4 for details of construction. 
As predicted, the cash flow, $C_{t}^{3}$, is negatively correlated with inflation risk measured by unanticipated changes in the CPI and with unanticipated changes in the GNPD. The magnitude of the $\mathrm{C}_{t}^{3}$ correlation with $\Delta \pi$ and UASA is small, but these were precisely the poorest proxies of unexpected inflation in the sense discussed following table 5 . The absolute sizes of the $C_{t}^{3}$ correlations are comparable to the cross-correlations of unexpected inflation measures across the two price indices, which are about 0.4 .

Thus, while a Treasury bill futures will not hedge CPI (GNPD) risk as well as a CPI (GNPD) futures contract, it performs as well for GNPD (CPI) risk as would a CPI (GNPD) contract. Since the true price risks of different agents in the economy may, in general, diverge as much as the price risks of the CPI versus the GNPD, the Treasury bill futures contract may be at least as adequate an omnibus hedge for price risk as a CPI (or a GNPD) futures contract. We have more to say on this issue in section 4 .

The risk-minimizing hedge ratio is also of interest. Consider the regression:

(10) $U \pi_{t}=\alpha+\beta C_{t}^{3}+w_{t}$,

where $U \pi_{t}$ is a measure of unexpected inflation and $C_{t}^{3}$ is the cash flow arising from a long position in a Treasury bill futures contract over period $t .22$ Our proposition (see section 2.4) predicts that $\beta$ equals $-1 /(1+\theta)$. of course, as discussed, if only the Weak FH holds, $\beta$ need not equal $-1 /(1+\theta)$ though it will remain strictly negative (i.e., inflation risk hedging potential will remain). The $w_{t}$ in equation (10) should be unpredictable given information at $t-1$. How should we interpret $w_{t} \neq 0$ in the context of our proposition? Consider two possibilities besides the possibility that the Strong FH fails.

${ }^{22}$ Equation (11) projects the risk to be hedged onto the hedging instrument. 
First, our measures of unexpected inflation may be only a proxy for the representative agent's price inflation, which is embedded in market prices, either because $\pi_{t}$ (measured) $\neq \pi_{t}$ ("true") or because our inflation expectations measures are not exact. In this view, $w_{t}$ is interpreted as a measurement error. Of course, with measurement errors, our estimates of the hedge ratio, $\beta$, may no longer be consistent. The problem of biased oLs estimation of $\beta$ is eliminated only if the measurement error is uncorrelated with $C_{t}^{3}$.

Second, additional information may become available after $t-1$, beyond the unexpected inflation from $t-1$ to $t$, that affects the market's revision in inflationary expectations. Alternatively, our estimated IMA $(1,1)$ model may not be the same as the model used by the market to form inflationary expectations. In any case, let us turn to the estimates of the hedging potential with the data at hand.

Before we turn to estimation of $\beta$, a possible complication may be induced by a shift in inflationary regime that took place around 1982. As widely discussed in the monetary economics literature, experts diagnosed a shift in monetary policy implementation during 1979-82--for instance, see Roley (1986) or Bradley and Jansen (1986). In this case, the coefficients of the inflation forecast revision process discussed in section 2.3 may be different in the pre- and the post-1982 periods. Some evidence on this issue is reported in table 7 . 
TABLE 7

RISK-MINIMIZING HEDGE COEFFICIENTS

$\mathrm{U} \pi_{t}=\beta C_{t}^{3}+w_{t}$

\begin{tabular}{|c|c|c|c|c|}
\hline \multirow[b]{2}{*}{ Proxy for $U \pi_{t}$} & \multicolumn{2}{|c|}{$76 Q 3-82 Q 4$} & \multicolumn{2}{|c|}{$83 Q 1-85 Q 1$} \\
\hline & $\beta$ & $\begin{array}{l}\text { isk } \\
\text { uctiona }\end{array}$ & $\beta$ & $\begin{array}{l}\text { isk } \\
\text { uction }\end{array}$ \\
\hline (a) UFH (FH, CPI) & $\begin{array}{l}-0.21 \\
(0.12)\end{array}$ & 338 & $\begin{array}{l}-1.25^{b} \\
(0.78)\end{array}$ & $388^{b}$ \\
\hline (b) UD (DRI, CPI) & $\begin{array}{l}-0.32 \\
(0.14)\end{array}$ & 408 & $\begin{array}{l}-1.10 \\
(1.08)\end{array}$ & 298 \\
\hline (c) UDRI (DRI, GNPD) & $\begin{array}{l}-0.20 \\
(0.09)\end{array}$ & 398 & $\begin{array}{l}-0.68 \\
(0.69)\end{array}$ & 328 \\
\hline
\end{tabular}

NOTE: The estimates of the intercept were always close to zero in simple regressions that included a constant. This finding of a zero intercept is foreshadowed in table 5 where the means of the variables in the regression were seen to be close to zero.

athe risk-reduction measure is simply the correlation.

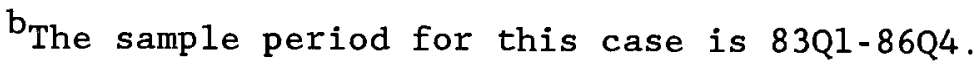

The few observations in the post-1982 period preclude a powerful test for a shift in the risk-minimizing hedge coefficients. Nonetheless, the qualitative evidence in table 7 seems to indicate such a shift, which is consistent with our arguments.

Our weak prediction was that we would observe hedging potential and that $\beta$ would be negative. This is confirmed. Consider the sharper prediction that $\beta=-1 /\left(1+\theta_{1}\right)$, as implied by the strong $\mathrm{FH}$ and our auxiliary assumptions. The univariate inflation model estimated in table 3 gives a $\theta_{1}$-estimate of -0.52 , which corresponds to an implied $\beta$ of around -2 . This sharp prediction for $\beta$ is rejected even after we make an allowance for the uncertainty of the $\theta_{1}$ estimate. The $\beta$-estimates in table 7 argue against the strong $\mathrm{FH}$ assuming 
that the inflation proxies used are unbiased estimates of the true inflation risk of concern to financial market participants.

\section{INFLATION RISK HEDGING: NEED AND COMPLICATIONS}

Having established that Treasury bill futures can hedge against inflation risk, we now ask whether there is a need for such hedging. We also discuss the multiperiod hedging problem, which introduces complications not present in the single-period situation examined in the empirical sections.

\subsection{Who Needs an Inflation Risk Hedge?}

Society as a whole may benefit or lose from inflation. But to the extent that the future rate of inflation is known, one cannot hedge against these costs in a rational market. ${ }^{23}$ Similarly if expectations are held in common ${ }^{24}$ --the assumption here and in the finance literature generally--it will not be possible to hedge against this inflation component.

23 A natural psychological propensity, which should be avoided, is to compare the risks of unexpected inflation against the background of the costs of anticipated inflation. The marginal risk imposed by unexpected inflation, given inflation risks and all other risks, is the quantity of interest. An alternate version of this risk is seen in discussions of risks to life. In that arena 10,000 additional cases of a cancer that otherwise causes 500 deaths per year seem more important than 15,000 incremental cases of a cancer claiming 100,000 individuals annually. See the discussion of framing in Kahneman et al. (1982).

${ }^{24}$ The formation of homogeneous inflationary expectations is aided by a market where assets trade that depend on inflationary expectations: Hayek (1945) is a classic exposition; Grossman and Stiglitz (1976, 1980) develop models that address information aggregation in competitive markets. To the extent that reduced divergence among agents' expectations about the rational expectation mitigates welfare losses from inflation risk, overall welfare will be improved by the identification of assets where individuals can trade on differential information about inflationary expectations. 
Whatever the costs of anticipated inflation, ${ }^{25}$ unexpected inflation imposes clear significant risks and real costs. ${ }^{26}$ There is substantial redistribution of risk between debtors and creditors when loan contracts are specified in nominal terms; workers' wages are only partially indexed with price level, while benefits such as pension payments are not indexed at all. 27 A11 assets denominated in nominal terms are at risk. By 1981, more than $\$ 1,680$ billion of listed bonds in the United States fell into this category. (Indeed the market value of nominal bonds exceeds that of equities.) Whether citizens gain or lose on net is not the critical question for our work (though the answer to it would tell us what sign to expect for an inflation risk premium). ${ }^{28}$ As long as some individuals are at risk from unexpected inflation (i.e., not perfectly balanced), a hedging instrument will be of use. Quite likely there would be hedgers on both sides of the market.

${ }^{25}$ Fully anticipated inflation may impose significant costs: utilities with regulated returns based on historical costs, workers stuck in a profession, or retirees with pensions fixed in nominal terms may be badly hurt when expected inflation is high; debtors, owners of real assets, tenants under rent control, and those who switch nimbly among sectors of the economy may benefit. There may be general benefits as well. The Keynesian macroeconomic paradigm suggests a strong argument in favor of nonzero inflation: adjustment to equilibrium entailing relative price adjustments is facilitated by overall inflation if there is downward price inflexibility (which is quite plausible for wages).

${ }^{26}$ Another type of inflation risk arises if general price level uncertainty is associated with relative price uncertainty. Lucas (1972) is the classic work. Patel and Zeckhauser (1985) argue that a common cost-of-living index is inadequate for heterogeneous agents given the empirical properties of prices. Their finding underscores the difficulty of providing adequate inflation hedges based on general contractual agreements.

${ }^{27}$ Card (1986) estimates that only about 108 of the U.S. labor force has substantial cost-of-1iving wage indexation.

${ }^{28}$ See Fischer (1986; section I) and cited references therein for further discussion of costs of both expected and unexpected inflation. 


\subsection{Costs of Inflation Risk}

The standard deviation of unexpected inflation is $3.1 \%$ (based on UD or UFH for the 1972-83 period--see table 4). Though this appears small in relation to the standard deviation of the returns on a broad equity index portfolio, it may be worth hedging against. (For 1926-81, Ibbotson and Sinquefield (1983, p. 36) find that annual stack returns had a standard deviation of $21.7 \%$.)

How costly is such inflation risk to an individual? Consider an individual with the constant risk aversion utility function $U=-e^{-a w}$, where $w$ is terminal wealth in thousands of real dollars. (For a $=0.02$, a parameter value we consider, such an individual would accept a certain $\$ 4,750$ in exchange for a 50-50 gamble on $\$ 10,000$ or $\$ 0$.$) If this individual is to receive$ a nominal terminal wealth of $\$ 1$ million, expected utility calculations show that he would be willing to pay $\$ 8,897$ to eliminate unexpected inflation uncertainty whose distribution is taken to be the same as that empirically observed for the 1972-83 period. ${ }^{29}$ Additional uncertainties may raise or lower the value of an inflation hedge depending on the utility function and the correlation between the risks.

In contrast to the utility-based example, a preference-free calculation can be based on the Capital Asset Pricing Model (CAPM). Suppose that we have only two classes of risky assets: stocks and single-period nominal bonds. Assume, using the historical values in Ibbotson and Sinquefield (1983), that the expected real return on stocks is 88 and the standard deviation is 20\%. The standard deviation of annual unexpected inflation has been about 58 for the

${ }^{29}$ For $a=0.01$, which implies that the 50-50 gamble of $\$ 0$ or $\$ 10,000$ is worth $\$ 4,875$, he would pay $\$ 4,583$ for a perfect hedge against inflation. 
past decade. For different values of the correlation between the prices of stocks and nominal bonds and the relative weights in the market portfolio, the CAPM provides us with the expected premium for bearing inflation risk. 30 To illustrate, let us fix the nominal debt-to-equity ratio at unity and the real riskless borrowing and lending rate at zero. If inflation has a correlation of 0.3 with equity returns, the removal of one unit of inflation risk is worth 1.028 in real return at the margin. If the correlation were 0.0 , it would be worth $0.5 \%$. These amounts are in line with the previous calculations using the utility function.

\subsection{On Using CPI Contracts}

Why, if inflation risk is important, should one not simply use the CPI futures contracts recently introduced on the Coffee, Cocoa, and Sugar Exchange, as the hedge? Barro (1986), for example, makes a case for CPI futures contracts and predicts success for them. Unfortunately, the CPI futures contract has failed to generate adequate trading interest to assure depth and efficiency. For instance, on June 30, 1986, after more than a year of trading, only 105 contracts were open; even worse, no contracts traded on this day. A number of explanations are possible.

First, there may have been a minimum-scale problem: the contract did not achieve sufficient volume and liquidity to become self-sustaining, perhaps because its exchange is not prominent. In addition, there are many measures

${ }^{30}$ With two risky assets and the riskless rate set to zero, the CAPM can be solved to obtain:

$$
E r_{2}=E r_{1}\left[(1-\delta) \sigma_{22}+\delta \sigma_{12}\right] /\left[(1-\delta) \sigma_{12}+\delta \sigma_{11}\right]
$$

Here subscripts 1 and 2 refer to the two different assets, Er denotes the expected returns, $\sigma$ denotes the variances/covariances, and $\delta$ denotes the proportion of the first asset to the sum of the two assets. 
of inflation. Perhaps the CPI does not sufficiently approximate the cost-ofliving index of most prospective hedgers. Conceivably the analysis of Barro and the one contained here are in error, or there may be no need for an inflation risk hedge. Or quite possibly the contract was formulated in a manner that was unappealing or inaccessible to the public. The Coffee, Cocoa, and Sugar Exchange is now reformulating its contract to be defined in terms of inflation rates, rather than in the levels of the CPI index, a change that may facilitate understanding. 31 Aron and Lazear (1985) reach a negative conclusion on the potential for an inflation-hedge contract. Their conceptual, not empirical, inquiry helped discourage the Chicago Mercantile Exchange from launching such a contract (personal commmunication, Lazear, 1986). Given the inadequacy of the current CPI instrument, the use of Treasury bill futures to hedge risk remains a viable option.

\subsection{Multiperiod Hedging}

If the world were kind to us analytically, (1) all contracts would be written at the beginning of one period and paid off at the end, and (2) expected inflation in the next period would be independent of observed inflation

${ }^{31}$ Since most agents are familiar with the CPI inflation rate, the readily understandable contract would be in terms of inflation and not in terms of the level. How many economists even know the latest CPI level? On the other hand, the inflation rate is widely discussed.

Second, money illusion may be more pervasive and significant than conventional wisdom suggests. Maybe Fisher (1928) was right after all. Indeed, Modigliani and Cohn (1979) conclude that money illusion was a major determinant of the behavior of U.S. equities in the 1970 s.

Third, and most simply, individuals may face only minimal net inflation risk. Minimal inflation risk in the aggregate is not sufficient to explain the failure of the CPI contracts; in fact, if inflation risk cancels out in the aggregate but individuals face risk, we would expect CPI futures contracts to be very successful because of the need for and feasibility of inexpensive risk spreading. 
in this period. The world is cruel. Contracts are written for varying lengths of time, and many expectations and practices in effect extend contracts much longer than their formal duration. Professors' salaries and rental apartments in private houses, for example, though renegotiated every year tend to $1 \mathrm{ag}$ behind inflation increases, perhaps because of money illusion or considerations of fairness. ${ }^{32}$ Regulatory proceedings, say on utility rates, are subject to political pressures, where exorbitance is measured in nominal terms. The prices of very long-term contracts, such as might be found with employment when there is substantial job-specific human capital, are sometimes contingent on increases in the price level. 33 More likely, however, prices beyond the initial period will reflect expected inflation over the duration of the contract; the complexities of multiperiod inflation risks introduce themselves. 34

${ }^{32}$ On fairness in pricing, see Kahneman, Knetsch and Thaler (1986).

${ }^{33}$ Mortgages tend to be written for a long period of time, thus encountering inflation risk. Variable-rate mortgages protect against such risk, assuming that inflation is a principal determinant of nominal interest rates. Interestingly, such mortgages have only recently come into widespread use.

Moreover, the upward and downward swings in interest rates tend to be capped, presumably to protect against risk, although this actually increases the risk of the real cost of the mortgage. However, if mortgagors are beneficiaries of other nominal contracts, some dampening of swings in nominal rates may be beneficial.

${ }^{34}$ If the inflation rate in period $t$ does not affect ex ante real returns or expected inflation in $t+1$, then an investor in nominal bonds is indifferent between buying a two-period bond and rolling over one-period bonds. By contrast, a worker with constant marginal product would reduce his risk if his wage was set at the beginning of each period. He will now get wages in the second period that account for the change in purchasing power from the first.

However, if inflation surprises in period $t$ are reflected in expected inflation in period $t+1$, an additional class of risk is imposed on two-period (multiperiod) contracts, namely the uncertainty about expected inflation for period $t+1$ as assessed at the beginning of period $t$. Even the nominal bond investor will be protected by rolling over contracts on a period-by-period basis. 
The dynamic problem of inflation risk in multiperiod settings is quite complicated. For instance, the inflation risk for a worker faced with nominal wage contracts can be quite different from the inflation risk for a investor in nominal financial instruments. Consider a two-period horizon with inflation rates that are independent between periods. Assume that the real marginal product of labor is the same in each period and that wages are set in nominal terms. A worker with wages set at the beginning of each period is better off than a worker with wages set for both periods. The former has an opportunity to get wages for the second period that account for the change in purchasing power experienced in the first period. In contrast, a investor in nominal bonds is indifferent between buying a two-period bond and rolling over one-period bonds if ex ante real returns are a constant. The result is readily understood by recognizing that the bond transaction is a purchase and resale while the employment transaction is a rental agreement.

Further, innovations in inflation during this period substantially affect expectations for following periods: our estimates, based on the model in table 1 , indicate that a 18 unexpected inflation in a year leads to an upward revision of 0.438 for expected inflation for the forthcoming year and 18 for the years beyond that. An individual with nominal contracts that extend beyond the year is at risk not only for this period's unexpected inflation, but for its contribution to (predicted impact upon) expected inflation in subsequent years. The weighting process to compute average duration of contracts is subtle, with weights adjusted not only for dollar amounts, but to allow for compounding within the year, and to permit declining effects over time of this year's unexpected inflation on post-year expected inflation. The impact of unexpected inflation on future expected inflation will still be important for 
applying our results to specific cases--the calculations will be tedious but straightforward.

\section{CONCLUDING COMMENTS}

Futures contracts on Treasury bills can reduce inflation risk by about 30-408. The expected cost of using such futures is close to zero. ${ }^{35}$ Treasury bill futures may remain the main means of hedging inflation risk since CPI futures contracts have not become well established.

Our analysis also bears on the portfolio strategy for obtaining outcomes that minimize real-return risk. Current practice capitalizes on the FH by undertaking a strategy of rolling over Treasury bills. Our finding that UFH risk correlates 33-38\% with cashflows from Treasury bill futures (in tables 6 and 7) indicates that an improved strategy is available. Such a strategy would roll over both Treasury bills and Treasury bill futures. Further, we conjecture that investors exposed to purchasing power risk of the Canadian dollar or the British pound can exploit our results as well, since (a) their inflation experience and their support for the FH is similar to that of the United States (see Patel (1986)) and (b) they have instruments analogous to U.S. Treasury bill futures.

The standard deviation of annual unexpected inflation over the 1953-84 period was approximately 2.18 . In these circumstances, we find that inflation risk (i.e., the variability in ex post purchasing power of nominal claims due

35 Monte Carlo simulations employed to assess this cost reaffirm the need for special care in econometric procedures when the variables have near-unit autoregressive roots. For the small sample sizes that we deal with ( $<50$ observations), standard tests would have rejected the UEH, whereas the simulations suggest that the OLS estimates could reasonably have arisen with the UEH being true. 
to unexpected inflation) can impose significant costs on individuals. Unexpected inflation has effects that carry beyond the period in which it occurs, influencing expectations of subsequent inflation and possibly affecting ex ante real rates of return as well. Either effect would magnify the costs associated with unexpected inflation.

An intriguing future investigation would be to examine the inflation risk of a representative diversified portfolio. But whatever such a study might show, the value of a hedging instrument for inflation risk is not to be underestimated: few individuals hold a fully diversified portfolio of assets. The explanation is more than ignorance. Substantial portions of individuals' holdings are in human capital, small businesses, or other hard-to-diversify assets. This implies that many individuals are likely to be exposed to significant inflation risk and can be helped by a strategy that reduces this risk at low cost. We recognize that many individuals are unconcerned by or indeed even unaware of inflation risk, perhaps because of the same factors that produce the more surprising ignorance associated with money illusion. Hedging against an underrecognized risk may be an acquired taste, or possibly even a merit good.

Our results support the weak Fisher Hypothesis for Treasury bill pricing and the Unbiased Expectations Hypothesis for the pricing of Treasury bill futures. 


\section{APPENDIX \\ MONTE CARLO SIMULATIONS TO ASSESS THE UEH}

Our first step for setting up simulations was to identify a time-series model for the Treasury bill prices, $B_{t}\left(\equiv F_{t}^{0}\right)$. $B_{t}$ is found to be (near) nonstationary. ${ }^{36}$ Formal statistical tests are in table A1.

The slow decay of the autocorrelations is consistent with a near nonstationary process. The results of the Fuller (1976) test based on the $t$ statistic of $\beta_{0}$ do not reject the hypothesis that $B_{t}$ is nonstationary. Thus, we model $B_{t}$, the 90 -day Treasury bill price, as a nonstationary process.

Assuming the $B_{t}$ has a unit autoregressive root, we consider a stationary model for $B_{t}$ in the differences. An adequate stationary autoregressive model (see Box and Jenkins (1976)) is found to be:

(A1) $\Delta \mathrm{B}_{\mathrm{t}}=\alpha+\sum_{i=1}^{6} \beta_{i} \Delta \mathrm{B}_{t-i}+\mathrm{n}_{\mathrm{t}}$

The choice of six lags is simply based on selecting the minimum number of lags that provides white noise residuals. The summary statistics from fitting the above model appear in table A2.

${ }^{36} \mathrm{~B}_{\mathrm{t}}$ may have only a near-unit autoregressive root if we believe that the possible range of interest rates is bounded. In this scenario, our simulations are still useful if $B_{t}$ behaves "locally" like a unit root process. 
TABLE A2

SUMMARY STATISTICS

\begin{tabular}{lccccccc}
\hline & $\alpha$ & $\beta_{1}$ & $\beta_{2}$ & $\beta_{3}$ & $\beta_{4}$ & $\beta_{5}$ & $\beta_{6}$ \\
& & & & & & & \\
Parameter estimates & -0.01 & 0.39 & -0.36 & 0.67 & -0.24 & 0.21 & -0.36 \\
t-statistic & -0.46 & 3.58 & -3.09 & 0.58 & -2.02 & 1.84 & -3.33 \\
Adjusted $\mathrm{R}^{2}=0.22$ & Degrees of freedom $=73$ & $\hat{\sigma}_{\mathrm{n}}^{2}=0.0529$ &
\end{tabular}

NOTE: Residual autocorrelations (not reported) are consistent with a white noise process--that is, not significantly different from zero.

We use the estimates shown in table A2 to set up our Monte Carlo simulations. For each simulation, we draw $200 \mathrm{n}$ 's (representing innovations in $B_{t}$ ) from a normal distribution with zero mean and variance $0.0529\left(\equiv \hat{\sigma}_{n}^{2}\right)$.

We use the $\beta$-estimates of table $A 2$ to create a simulated $B_{t}$-series, $\hat{B}_{t}$. We also construct one-step- through six-step-ahead optimal forecasts for the $\hat{B}_{t}$ series given the true generating process. These forecast series, $\hat{F}_{t-k}^{k}$, represent futures prices assuming that futures prices are efficient unbiased forecasts of the $\hat{B}_{t}$ series. We drop the first 90 simulation values to mitigate start-up effects.

Next, we sample every third observation of $\hat{B}_{t}$ and the associated onestep-ahead through six-step-ahead forecasts, ft-1 through fF-6. This corresponds to the situation where we have only futures contracts with a quarterly maturity cycle. We then perform six ols-regressions, each with 31 observations (corresponding to the sample size in table 1). The regressions are of $\hat{B}_{t}$ on a constant and the f-series. We save the coefficient estimates (corresponding to $\alpha$ and $\beta$ in table 1 in the main text) of each of the six regressions in 1000 simulations. The results appear in figure 1 in the main text. 
We assess the power of tests based on the results in table 1 and figure 1 by considering simulations where the true $\beta$ is 0.1 (rather than 1.0 as predicted by the UEH). We repeat the simulation method discussed above to generate $\hat{B}_{t}$. However, in this set of simulations the $\hat{F}_{t-1}^{1}$ through $\hat{F}_{t-3}^{3}$ are $0.1 \times \hat{B}_{t}+u_{t}$ where $u_{t}$ is normal i.i.d. with standard deviation corresponding to the $\sigma_{\mathrm{u}}$ values in table 1 . Following the earlier simulations, we save the coefficients of each of three regression in 1000 simulations. The results are in figure 2 in the main text. 


\section{REFERENCES}

Aron, D., and E. Lazear, 1985. "An Analysis of the Marketability of a CPI Future," mimeo, University of Chicago.

Bradley, M., and D. Jansen, 1986. "Federal Reserve Operating Procedure in the Eighties," Journal of Money, Credit and Banking, v. 18: 323-335.

Barro, Robert J., 1986. "Futures Markets and Fluctuations in Inflation, Monetary Growth, and Asset Returns," Journal of Business, vol. 59 (pt. 2): $\mathrm{S} 21-\mathrm{S} 38$.

Bodie, Zvi, 1976. "Common Stocks as a Hedge Against Inflation," Journal of Finance, pp. 459-470.

Branch, B., 1978. "Testing the Unbiased Expectations Theory of Interest Rates," in: G. Gay and R. Kolb, eds., Interest Rate Futures: Concepts and Issues, 1982, Robert F. Dame (Richmond, VA), 143-58.

Card, D., 1986. "An Empirical Model of Wage Indexation Provisions in Union Contracts," Journal of Political Economy, Vo1. 94, No. 3, part 2, June: pp. $5144-75$.

Ederington, L., 1979. "The Hedging Performance of the New Futures Market," Journal of Finance, v. 34, March: 157-70.

E1ton, E., M. Gruber, and J. Rentzler, 1984. "Intra-day Tests of the Efficiency of the Treasury Bill Futures Market," Review of Economics and Statistics, v. LXVI, n. 1, February: 129-34.

Fama, E., 1975. "Short-Term Interest Rates as Predictors of Inflation," American Economic Review, June, 65: 269-82.

Fama, E., and W. Schwert, 1977. "Asset Returns and Inflation," J. of Financial Economics, v. 5, November: 115-46.

Fama, E., and M. R. Gibbons, 1982. "Inflation, Real Returns, and Capita1 Investment," Journal of Monetary Economics, 9: 297-323.

, 1984. "A Comparison of Inflation Forecasts," Journal of Monetary Economics 13, pp. 327-348.

Fama, E., and J. Macbeth, 1974. "Tests of the Multiperiod Two-Parameter Mode1," Journal of Financial Economics, Vo1. 1, May, pp. 43-66.

Fischer, S., 1986. Indexing, Inflation and Economic Policy. M.I.T. Press (Cambridge, Mass.).

Fisher, Irving, 1928. The Money Illusion. 
Fuller, W., 1976. Introduction to Statistical Time Series. John Wiley and Sons (New York).

Granger, C., and P. Newbold, 1987. Forecasting Economic Series, second edition. Academic Press.

Granger, C., and R. Engle, 1984. "Dynamic Mode1 Specification with Equilibrium Constraints," working Paper, U. C. at San Diego.

Ibbotson, R. G., and R. A. Sinquefield, 1982. Stocks, Bonds, Bills and Inflation: The Past and the Future, Monograph \#5.

Jarrow, R., and G. Oldfield, 1981. "Forward Contracts and Futures Contracts," $J$. of Financial Economics, v. 9, n. 4: 373-82.

Lang, R., and R. Raasche, 1978. "A Comparison of Yields on Futures Contracts and Implied Forward Rates," in: G. Gay and R. Kolb, eds., Interest Rate Futures: Concepts and Issues, 1982, Robert F. Dame (Richmond, VA), 123-42.

Lucas, R., Jr., 1972. "Expectations and the Neutrality of Money." $J$. Econ. Theory, 4, n. 2: 102-24.

Miller, M., and C. Upton, 1974. Macroeconomics: A Neoclassical Introduction, R. D. Irwin (Homewood, IL).

Modigliani, F., and R. Cohn, 1979. "Inflation, Rational Valuation and the Market," Financial Analysts Journal, March-April, pp. 24-44.

Nelson, C., and G. Schwert, 1977. "Short-Term Interest Rates as Predictors of Inflation: On Testing that the Real Rate of Interest Is Constant, "American Economic Review, June 67: 478-86.

Pate1, J., and R. Zeckhauser, 1985. "Indices, Fitting and Fair, for Cost-ofLiving and Asset Portfolios," manuscript, John F. Kennedy School of Government, Harvard University.

Pate1, J., 1986. "The Fisher Hypothesis and Real Returns," Discussion Paper 155D, John F. Kennedy School of Government, Harvard University.

Roley, V., 1986. "Market Perceptions of U.S. Monetary Policy Since 1982," Federal Reserve Bank of Kansas Economic Review, May: 27-40.

Vining, D., and T. Elterowski, 1976. "The Relationship between Relative Prices and the General Price Level," American Economic Review, September, v. 66: 699-706.

Wachter, M., and O. Williamson, 1978. "Obligational Markets and the Mechanics of Inflation," Bell Journal of Economics, v. 9 (Fall): 549-71.

Yule, G., 1926. "Why Do We Sometimes Get Nonsense Correlations Between This Series? - A Study in Sampling and the Nature of Time Series, "Journal of Royal Statisticians Society, vol. 89: pp. 1-64.

Zellner, A., 1985a. "Bayesian Estimation and Prediction Using Asymmetric Loss
Functions," forthcoming Functions," forthcoming Journal of American Statistical Association. 